\title{
Avaliação da tutoria no Curso de Especialização em Negociação Coletiva / Modalidade a Distância (MPOG-EA/UFRGS)
}

\author{
Diogo Joel Demarco, EA/UFRGS, diogo.demarco@ufrgs.br \\ Elaine Di Diego Antunes, EA/UFRGS, elaine.antunes@ufrgs.br \\ Ivan Antônio Pinheiro, EA/UFRGS, iapinheiro@ea.ufrgs.br \\ Nádia Brunetta, EA/UFRGS, nabrunetta@yahoo.com.br
}

\begin{abstract}
Resumo
O presente trabalho objetiva avaliar a atuação dos tutores do Curso de Especialização em Negociação Coletiva (NEGCOL-EA/UFRGS), ofertado na modalidade a distância. A justificativa deste estudo visa aperfeiçoar o papel desempenhado pelo tutor no processo de ensino-aprendizagem mediado por TICs. Na discussão teórica são apresentadas noções conceituais acerca do papel dos tutores no processo de ensinoaprendizagem mediado por tecnologias, bem como da importância da avaliação da atuação dos mesmos. Em termos metodológicos, realizou-se um levantamento com delineamento exploratório-descritivo, sendo que os dados foram coletados via web com 288 alunos, cujas respostas foram analisadas por meio de estatísticas simples. Também se fez uso de dados secundários. Os principais resultados indicam que a avaliação do desempenho dos tutores, tanto nas avaliações reativas dos alunos ao final das disciplinas, como na avaliação final do curso, foi bastante positiva. Há fortes indícios de que a estrutura de tutoria adotada pelo curso tenha contribuído para o bom desempenho dos tutores. Na avaliação pela coordenação do curso fica em aberto a questão quanto ao modelo de estruturação da tutoria, se por disciplina ou permanente, tendo em vista que no caso do curso foi uma mescla de ambos os modelos.
\end{abstract}

Palavras Chave: Tutoria; Avaliação do tutor; Ensino a Distância.

\section{Evaluating tutoring on the Specialization in Collective Bargaining Course / Distance Learning/Teaching Mode (MPOG-EA/UFRGS)}

\begin{abstract}
This study aims to evaluate the performance of the tutors on the Specialization in Collective Bargaining Course (NEGCOL-EA/UFRGS), offered in the distance learning/teaching mode. The rationale for this is to enhance the role of the tutor in the teaching-learning mediated by TICs. The theoretical discussion presents the conceptual notions regarding the role of tutors in teaching-learning situations mediated by technology, as well as the importance of assessing their performance. In terms of methodology, a descriptive-exploratory survey was carried out with data being collected via the web from 288 students, whose responses were analyzed using simple statistics. Secondary data were also used. The main results indicate that the assessment of the tutors' performance, both in the students' reactive evaluations at the end of the disciplines and in the final evaluation of the course was very positive. There is strong evidence that the tutoring structure adopted in the course has contributed to the tutors' good performance. In the assessment made by the course coordination committee the model of the tutoring structure remains an open issue, whether by subject or permanent, as in the case of this course there was a mix of both models.
\end{abstract}

Keywords: Tutoring; Tutor Assessment; Distance Learning/Teaching 


\section{INTRODUÇÃO}

A crescente demanda por cursos a distância no país se manifesta igualmente entre as organizações e trabalhadores do setor público, impulsionada não somente pela expansão da tecnologia, mas principalmente pela ampliação das ações do Estado por meio das políticas públicas e pela possibilidade de progressão na carreira através da elevação da escolaridade. É nesse contexto que, por meio de parceria entre a Escola de Administração da UFRGS e a Secretaria de Recursos Humanos do Ministério do Planejamento, Orçamento e Gestão (MPOG), surgiu o Curso de Especialização em Negociação Coletiva - modalidade a distância; planejado com o propósito de ampliar as competências dos servidores públicos federais no que se refere à democratização das relações de trabalho e a institucionalização da negociação coletiva na Administração Pública Brasileira.

Tal objetivo visa fomentar uma mudança de cultura no âmbito das relações de trabalho nas organizações públicas brasileiras, criando uma massa crítica de servidores públicos federais - da administração direta, autárquica e fundacional - capazes de atuar nos processos de negociação coletiva no setor público. Dessa maneira, o curso foi estruturado na modalidade a distância, com a intenção de manter os alunos nos seus locais de trabalho e promover a aplicabilidade dos conteúdos teóricos desenvolvidos nas disciplinas, no contexto profissional dos servidores públicos. Para além das atividades na modalidade a distância, que promoviam a socialização de conhecimentos e interação entre os participantes, realizadas no ambiente de aprendizagem virtual (AVA), ocorreu um encontro presencial destinado à integração dos participantes e avaliação dos conteúdos apreendidos. O final dessa trajetória culminaria num projeto que serviria como base para elaboração do trabalho de conclusão de curso - requisito obrigatório para a obtenção da certificação pretendida, desde que atendidos os critérios de avaliação previstos no projeto pedagógico.

No total, 574 discentes foram matriculados no curso e alocados em sete polos distribuídos pelas regiões do país: Belém (PA); Belo Horizonte (MG); Brasília (DF); Porto Alegre (RS); Recife (PE); Rio de Janeiro (RJ) e São Paulo (SP). Os alunos contaram com diversos recursos do ambiente virtual NAVi - chats, fóruns temáticos, biblioteca virtual, vídeos, teleconferências, entre outros - no período de oferta das disciplinas, durante o processo de orientação do Trabalho de Conclusão do Curso (TCC) e na preparação para as bancas. Para atender os objetivos de mediação do conhecimento e interação, em todos esses momentos do curso, os alunos contaram com o apoio de tutoria.

O acompanhamento tutorial torna-se elemento fundamental para assegurar o desenvolvimento e o aproveitamento dos eventos realizados no curso a distância. $\mathrm{O}$ sistema de tutoria, nesta perspectiva, muito mais que um aspecto estrutural e de apoio ao estudante, é visto como elemento central no atendimento à educação individualizada e colaborativa, isto é, como uma estratégia de abordagem pedagógica centrada no ato de aprender que põe à disposição do estudante todos os recursos que irão permitir a consecução dos objetivos previstos no curso, desenvolvendo nos alunos uma maior autonomia em seu percurso de aprendizagem. Conforme Nevado (2005), a função dos professores e tutores é de promover a aprendizagem, através de um processo de diálogo onde o conhecimento é produzido a partir deste movimento, entre tutores, professores, alunos, avaliação e conteúdos.

Ao todo, cerca de 70 tutores foram envolvidos no decorrer dos diversos momentos do curso. Na tutoria das dez disciplinas ofertadas (e nas recuperações das mesmas) havia 66 diferentes tutores, alguns dos quais atuando em mais de uma disciplina. Nesta etapa, a equipe era formada por 20 tutores e um tutor-facilitador, 
responsável pelo auxílio dos professores na organização de cada disciplina (foram sete as disciplinas que contaram com um tutor-facilitador). No Encontro Presencial 1 atividade de integração e avaliação - realizado ao final das disciplinas, em cada um dos sete polos presenciais, nos dias 15 e 16 de abril de 2010, 17 tutores participaram como moderadores das atividades. Na tutoria de apoio à orientação, na fase de elaboração do trabalho de conclusão de curso, 21 tutores apoiaram o processo, cabendo ao professor acompanhar o atendimento aos alunos, através da mediação realizada pelos tutores. Durante a etapa de oferta das disciplinas, os tutores foram alocados por turmas de 30 alunos, distribuídas geograficamente por polos. Após a oferta da disciplina de Metodologia Científica, optou-se por realizar Seminários Temáticos de Monografia com as turmas reorganizadas, não mais pelo critério de localização geográfica e sim de acordo com o tema escolhido pelo aluno para o desenvolvimento do TCC.

A seleção de tutores foi realizada considerando o conhecimento específico sobre o tema da disciplina e o desempenho destes em atividades (de tutoria) anteriores em cursos EAD ministrados pela Escola de Administração/UFRGS. A escolha da equipe de tutores foi responsabilidade dos professores. Todos os tutores selecionados passaram por uma das edições de capacitação ofertadas pelo Curso NEGCOL, totalizando mais de 12 horas de treinamento entre atividades presenciais e a distância, realizadas no decorrer do ano de 2009. Por sua vez, a coordenação de tutoria, função desempenhada por um profissional, acompanhava o desempenho dos tutores e sua respectiva avaliação, buscando manter os melhores profissionais atuantes no curso. Os tutores que apresentavam um desempenho abaixo do esperado (considerado fraco) foram orientados a realizar novamente a capacitação. Eles eram reavaliados e, caso não melhorassem seu desempenho, eram desligados do curso. Assim, a avaliação do trabalho dos tutores foi realizada de forma contínua, por meio do uso de diferentes instrumentos e, especialmente pelos próprios alunos, através de pesquisas de reação realizadas no AVA ao final de cada disciplina, buscando considerar as contribuições dos tutores para o aprendizado dos alunos nas atividades síncronas e assíncronas.

Enfim, como ressaltam os dados do Censo EAD.BR (2012), realizado pela ABED, o universo de acompanhamento e de apoio ao aluno recebe diferentes papéis e nomenclaturas, o que muitas vezes dificulta a coleta das informações. No entanto, o mais importante, é observar que a educação a distância, inicialmente, preocupava-se com o conteúdo do curso e os materiais de ensino, e hoje há quase uma unanimidade na importância da valorização do acompanhamento e apoio ao aluno como um dos critérios de qualidade dos cursos e de condição para diminuição da evasão.

A tutoria tornou-se uma preocupação das instituições que oferecem educação a distância, seja nos cursos autorizados, seja nos livres ou corporativos. $\mathrm{O}$ apoio da tutoria para oferecer suporte ao aluno em termos pedagógico, de conteúdo, tecnológico e afetivo está sendo um esforço constante das instituições (CENSO EAD.BR, 2012, p. 45).

Diante do cenário problematizado, a questão norteadora deste artigo é: qual a avaliação que os alunos e a coordenação do Curso de Negociação Coletiva fazem da atuação dos tutores durante a realização das diferentes etapas do referido curso de especialização? Esta reflexão permitirá uma análise das principais questões apontadas pelos alunos e poderá oportunizar um aperfeiçoamento do papel desempenhado pelo tutor no processo de ensino-aprendizagem mediado por tecnologias de informação e comunicação (TICs), bem como contribuições no tocante à estrutura e organização dos cursos realizados a distância, os quais requerem orientações de grande quantidade de alunos, poder-se-ia dizer, um processo de ensino-aprendizagem em massa, mas com uma demanda de atuação dos tutores à um atendimento personalizado, direto e próximo ao aluno. 


\section{REVISÃO TEÓRICA}

\subsection{Desafios da Tutoria em EAD, mediada pelas TICs}

A demanda por cursos a distância cresce vertiginosamente no país e no mundo, impulsionada não somente pela expansão da tecnologia, mas principalmente pela possibilidade de o estudante desenvolver autonomia no controle do próprio tempo e ritmo de aprendizagem. De fato, o incremento das TICs facilita o processo de comunicação e interação, mas por si só não garante a aprendizagem dos alunos. Para Rosini (2007), a educação a distância deve procurar inverter alguns paradigmas, principalmente quanto à produção de saber e à sua transmissão. Para o autor, a EAD:

Vem seguindo o mesmo ritmo da educação presencial, isto é, envia material escrito aos alunos (no caso de instituições de ensino), mantém contato com eles por qualquer via de comunicação e, ao final do curso, emite um diploma. Como se vê, o problema é que a maioria dos cursos presenciais e a distância apenas informa os alunos, esquecendo-se de formá-los como cidadãos viventes em sociedades (ROSINI, 2007, p. $65)$.

Para superar a mera transmissão de informações, prática comum em muitos cursos (sejam eles presenciais ou na modalidade EAD) e estimular o processo de construção conjunta do conhecimento, surgem ferramentas que possibilitam a colaboração mútua dos estudantes e partícipes do processo (tutores e professores). Essa estratégia propicia um ambiente educacional colaborativo através da utilização de recursos tecnológicos.

Uma característica básica da aprendizagem colaborativa é desenvolver um ambiente que incentive o trabalho em grupo, respeitando as diferenças individuais. Todos os integrantes possuem um objetivo comum e interagem entre si em um processo em que o aluno é um sujeito ativo na construção do conhecimento, enquanto o educador é um mediador, orientador e condutor do processo educativo (ROSINI, 2007, p. 66).

Diante de uma grande diversidade de tecnologias do conhecimento, o papel do tutor em EAD é crucial, pois ele é o responsável pelo contato direto com os alunos. $\mathrm{O}$ tutor deve estar atento ao processo, para que seja capaz de analisar as características de cada aluno e valorizar suas diferenças, estimular novas ideias, desenvolver a capacidade de aprender a pensar. Neste sentido, a orientação e a diretividade são fundamentais para que o material instrucional utilizado no curso realize o objetivo que deve caracterizá-lo (ROSINI, 2007). No próximo item serão apresentadas algumas especificidades do papel exercido pelos tutores de cursos ofertados na modalidade de educação a distância.

\subsection{Papel da tutoria em EAD}

Os componentes integrantes da modalidade de ensino a distância são representados simbolicamente, na análise de Iahn (2002), por uma estrela de 5 pontas que correspondem ao professor, ao tutor, a avaliação, ao material didático e ao aluno. $\mathrm{Na}$ perspectiva desse autor, os componentes se relacionam de forma integrada, com o suporte das tecnologias de informação e comunicação, possibilitando o funcionamento adequado do processo e garantindo a apreensão e incorporação do conhecimento pelos alunos. A ausência de um desses componentes prejudicaria o processo de ensino e aprendizagem, portanto, para que sejam obtidos resultados satisfatórios, a presença desses componentes é importante.

Em contextos de EAD, a tecnologia é facilmente incorporada na atuação, mas esta modalidade de ensino exige maior envolvimento, dedicação e responsabilidade dos atores envolvidos no processo, especialmente dos tutores, que atuam na linha de frente 
dos cursos e em contato direto com os alunos. Como destacam os Chotguis (2005) e Longo (2010), cabe ao tutor o cumprimento do papel de mediador durante o processo ensino e aprendizagem, facilitando a aplicação e compreensão dos conteúdos para garantir a construção do conhecimento de maneira integrativa. Para Bentes (2008), o tutor é o agente motivador/orientador que irá acompanhar o aprendizado do aluno durante todo o processo. Ele assume características inerentes à sua função para trabalhar na EAD e:

Deve saber lidar com os ritmos individuais diferentes de cada aluno, apropriar-se de novas TICs, dominar as técnicas e instrumentos de avaliação, ter habilidades de investigação, utilizar novos esquemas mentais para criar uma nova cultura indagadora e plena em procedimentos de criatividade e ter disponibilidade para intervir a qualquer momento (BENTES, 2008, p. 167).

Na opinião de Maia e Mattar (2007), o tutor é responsável pelo contato inicial com a turma, que pode acontecer por meio do envio de uma mensagem de apresentação e boas-vindas, por exemplo. Ele também é responsável por gerar um senso de comunidade na turma que conduz, desempenhando assim um papel social.

Uma das funções mais importantes do tutor é justamente dar feedback constante a seus alunos. Em sala de aula, é possível dar feedback automático para os alunos e por vários canais: verbal, gestual, visual, auditivo, pela maior ou menor proximidade etc. Já a distância, o aluno se sente mais abandonado, e os canais são reduzidos, portanto o feedback torna-se um elemento crítico para reforçar o aprendizado. A orientação extra-aula para os alunos e o suporte, que podem ser fornecidos por um professor, tutor ou monitor, são elementos críticos para o sucesso de um curso a distância (MAIA; MATTAR, 2007, p. 91).

São atribuídas ainda funções pedagógicas e intelectuais ao tutor, tais como: incentivo à pesquisa e mediação de discussões, portanto, é essencial que as instituições de ensino se proponham a realizar programas contínuos de desenvolvimento e capacitação de tutores. Bentes (2009), ao ressaltar a relevância dos tutores como um dos componentes da EAD, citando a figura simbólica da estrela de cinco pontas proposta por Iahn (2002), destaca a importância da avaliação do trabalho dos mesmos como instrumento para melhorar suas atividades e práticas profissionais, identificando quatro diferentes tipos de avaliação dos tutores: a autoavaliação; a avaliação do tutor pelo aluno; a avaliação do tutor pela instituição; e a avaliação do tutor pelo professor especialista. No próximo item serão apresentadas algumas características do processo de avaliação dos tutores, com ênfase para a avaliação dos tutores pelos alunos e pela instituição.

\subsection{Avaliação do tutor pelo aluno}

A avaliação é uma constante em todas as esferas da vida, pessoas avaliam e são avaliadas em diferentes contextos e situações. Em ambientes educacionais a avaliação é uma atividade habitual e precisa estar a serviço da aprendizagem para que seja possível identificar se os objetivos estabelecidos para o processo de ensino-aprendizagem estão sendo atingidos. Na opinião de Bentes (2009), é importante que o aluno reflita sobre a participação do tutor no seu processo de aprendizagem, para que ele seja capaz de avaliar se o papel exercido pelo tutor foi, de fato, significativo durante o curso. Esta reflexão pode ser pautada em critérios relacionados à agilidade do atendimento prestado pelo tutor e na qualidade das respostas, isso significa que um pronto atendimento é esperado, mas os alunos também esperam que sejam apontadas as soluções ou possibilidades daquilo que foi demandado. 
Cada instituição de ensino elabora o seu instrumento de avaliação, de acordo com as especificidades de cada curso, mas é comum que sejam submetidas aos alunos questões acerca do perfil apresentado pelos tutores, na tentativa de identificar aspectos relacionados a cooperação do tutor, domínio de conteúdos, receptividade, clareza, objetividade, qualificação, interesse e eficiência.

\subsection{Avaliação do tutor pela instituição}

Os tutores interagem diretamente com os alunos e, por geralmente estarem mais acessíveis do que os demais atores envolvidos no processo de ensino-aprendizagem, podem se tornar alvos de críticas pessoais, que extrapolam o seu poder de atuação. As instituições, portanto, devem preocupar-se com a qualidade do processo de aprendizagem, mas, sobretudo perceber que parte da responsabilidade recai sobre a atuação do tutor.

Dessa maneira, cabe à instituição avaliar o corpo docente que constitui a equipe de tutores. Um fator muito importante é a busca por conhecimento e qualificação constante por parte do tutor - isso contribui para a sua avaliação. A instituição de ensino espera que o tutor atenda prontamente aos questionamentos, dúvidas e ansiedades do aluno em tempo e conteúdo. Significa que, para uma instituição de $\mathrm{EAD}$, o tutor é o espelho da instituição; quanto mais ágil e com conteúdo forem as respostas, melhor o aluno perceberá o quanto a instituição é responsável (BENTES, 2009, p. 168).

Cada sistema de avaliação depende dos modelos adotados e das diretrizes estipuladas nos projetos pedagógicos, institucional e de curso, entretanto, independentemente do sistema utilizado, a avaliação do tutor é considerada de grande importância. Assim, tutores bem preparados para o uso das tecnologias de informação e comunicação disponíveis, que apresentem domínio do conteúdo em sua área de atuação e que tenham uma postura adequada de atendimento aos alunos certamente contribuirão para que os resultados esperados sejam alcançados.

\section{PROCEDIMENTOS METODOLÓGICOS}

O presente artigo contempla um levantamento com delineamento exploratóriodescritivo, sendo que os dados foram coletados via web entre os alunos matriculados no curso e as respostas foram analisadas por meio de estatísticas simples (percentuais e médias) com o auxílio do pacote estatístico SPSS. A pesquisa de satisfação foi aplicada entre os alunos concluintes do Curso de Especialização em Negociação Coletiva. Entre os quinhentos e setenta e quatro (574) alunos matriculados no curso, duzentos e oitenta e oito (288) responderam os questionários disponibilizados virtualmente através do link http://www.ea.ufrgs.br/limesurvey/index.php?sid=87798\&newtest=Y\&lang=pt-BR.

Considerando que a população pesquisada foi composta por 574 alunos, o retorno da avaliação do curso efetuada no período do dia 01/02/2011 a 04/02/2011 (ficando no ar por apenas 4 dias) foi bastante significativo. Obteve-se $50 \%$ de retorno, o que representa uma margem de erro de 4,08, com intervalo de confiança de $95 \%$, índice considerado alto para pesquisas realizadas via web. A amostra é representativa de todos os polos e órgãos ou entidades nas quais os alunos do curso estão alocados. Para fins deste estudo serão analisados os dados referentes à avaliação dos tutores pelos alunos. Outras técnicas de coleta usadas, visando à triangulação das informações, foram: pesquisa em dados secundários em relatórios gerenciais e informações acadêmicas do curso. 


\section{RESULTADOS E DISCUSSÃO}

No âmbito do curso NEGCOL a Coordenação do curso contou com a seguinte estrutura para as atividades de tutoria a distância: (1) Coordenador de Tutores; (2) Capacitador técnico (em EAD) de Tutores; (3) Selecionador e Capacitador (de conteúdo) do tutor (Professor do curso); (4) Tutor-Facilitador e (5) Tutor-Especialista (cabendo a esse as seguintes atividades: coordenar e organizar chats e fóruns; esclarecer dúvidas dos alunos, suscitar o debate a fim de promover e propiciar o aprendizado, corrigir trabalhos e provas).

Dada a relevância do papel no referido curso pelo quantitativo de tutores envolvidos e pela própria estrutura do mesmo, baseada em disciplinas temáticas (oito ao todo) neste estudo se prioriza a avaliação da atuação dos denominados tutoresespecialistas. Tal avaliação se dará a partir dos dados extraídos das avaliações realizadas pelos próprios alunos e pela coordenação do curso, combinando assim elementos de dois tipos de avaliação dos tutores: a avaliação do tutor pelo aluno e a avaliação do tutor pela instituição, conforme proposto por Bentes (2009).

\subsection{Avaliação dos tutores pelos alunos}

Neste tópico são apresentados os resultados da avaliação de reação efetuada pelos alunos ao término de cada disciplina e a avaliação dos tutores no apoio ao processo de orientação do TCC. Em relação à avaliação das disciplinas, foram adotados como critérios: o retorno do tutor em tempo razoável; o feedback em relação às atividades realizadas, o comprometimento em relação a aprendizagem dos alunos e capacidade de associar os conteúdos a situações práticas. No gráfico 1 constata-se que a avaliação geral dos alunos em relação ao trabalho dos tutores foi bastante positiva nas diferentes disciplinas, variando entre 78 a $93 \%$ o nível de satisfação.

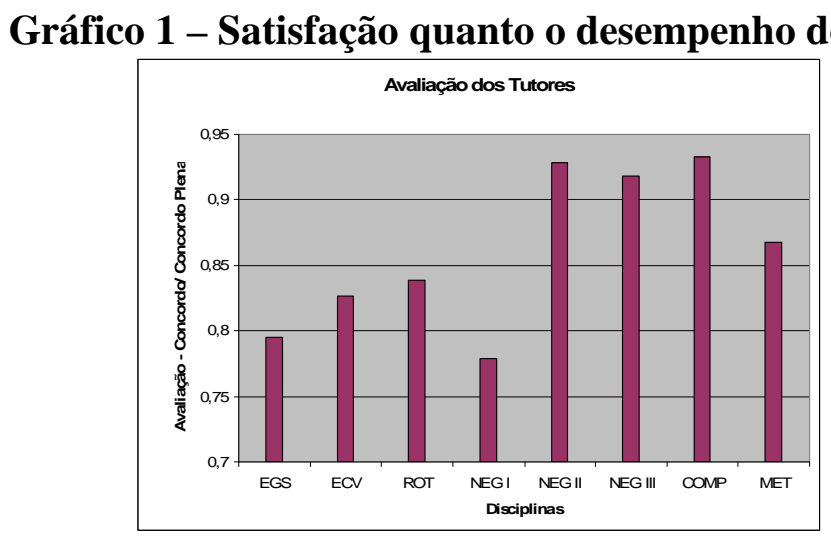

Fonte: Relatório Executivo do Curso NEGCOL

O gráfico 2 apresenta as variáveis utilizadas para avaliação do desempenho dos tutores durante o desenvolvimento do trabalho de conclusão de curso. Para tanto, utilizou-se uma escala de 01 (discordância) a 05 (concordância). A média do conjunto das variáveis avaliadas demonstra satisfação dos alunos neste quesito $(3,84)$. Destacamse os itens: cordialidade $(4,34)$, conhecimento metodológico $(4,03)$, conhecimento sobre o tema $(3,89)$ e pronto atendimento (com 3,89 de média). 
Gráfico 2 - Avaliação dos tutores no desenvolvimento do TCC

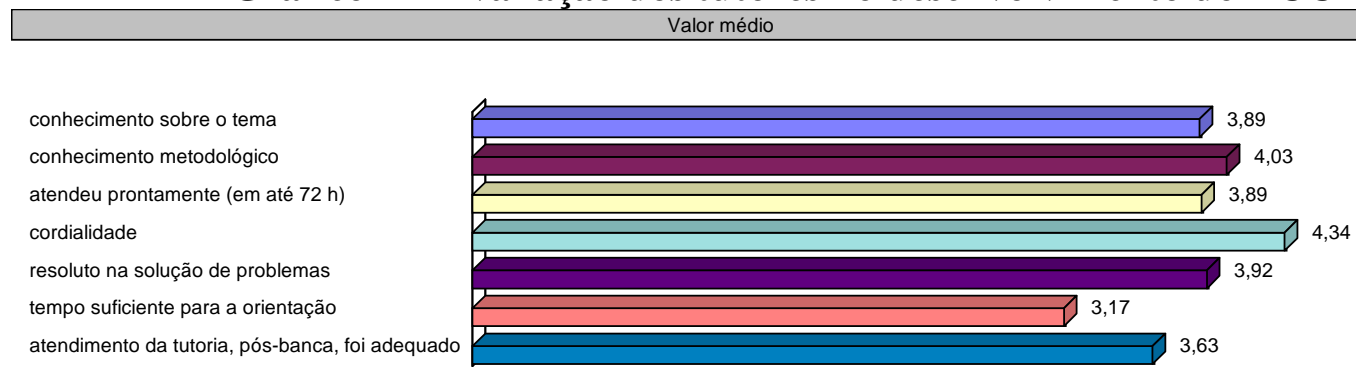

Fonte: Pesquisa de Avaliação geral do Curso

O resultado da aferição demonstra um elevado nível de satisfação por parte dos alunos. Tomando-se apenas o somatório das respostas dos itens 4 e 5 da escala observase que: $76 \%$ dos alunos indicaram que na maior parte das vezes o tutor demonstrou cordialidade, $66 \%$ responderam que na maioria das vezes o tutor atendeu prontamente (em até 72 horas), $66 \%$ dos alunos reconheceram o domínio metodológico por parte dos orientadores, $63 \%$ admitem que o tutor demonstrou conhecimento temático, $62 \%$ consideraram que o tutor foi resoluto no encaminhamento das soluções para os problemas apresentados, $56 \%$ consideraram que o atendimento da tutoria, pós-banca, foi adequado. Todavia, $42 \%$ (dentre os que assinalaram 4 ou 5 na escala), consideraram que o tempo de orientação, que inclui as disciplinas de Metodologia Científica e Seminários Temáticos de Monografia, foi suficiente e adequado para o cumprimento das etapas previstas (durante a construção do TCC).

\subsection{Perspectiva da coordenação do curso quanto à estrutura de tutoria}

Nos cursos de educação a distância, dois modelos de tutoria poderão ser utilizados: 1) do tutor permanente, aquele que acompanhará a mesma turma durante todo o curso independentemente da disciplina; ou, 2) do tutor-especialista, situação em que as turmas, a cada disciplina, experimentam contato com tutores escolhidos em razão do domínio vis-à-vis aos conteúdos da hora. Ainda, tanto ao primeiro, quanto ao segundo modelo, dependendo do número de alunos, poderá ser acrescida uma função intermediária: quer seja através do tutor-coordenador quer seja via tutor-facilitador. No curso NEGCOL optou-se pelo tutor-coordenador e pelo tutor facilitador, ambos mediadores entre os diferentes agentes do processo de ensino-aprendizagem e pelo tutor-especialista (escolhido e capacitado pelo professor responsável pela disciplina).

Por evidente que os modelos apresentam vantagens e desvantagens: o primeiro, em circunstância observada já na segunda ou terceira disciplina, facilita e promove o maior entrosamento, bem como antecipa a familiaridade entre a turma e o tutor, o que, em vista das tensões e das dificuldades intrínsecas ao ensino à distância, não é de somenos importância; ademais, de regra, tem mais facilidade, na medida em que progride o curso, apresentar os conteúdos de modo integrado. Já o segundo, admitindose que poucos tutores dominam vários campos de conhecimento (pelo menos é o que a evidência empírica demonstra), tem a vantagem ressaltada na razão direta da profundidade e especificidade do domínio abordado, bem como da distância (e necessidade) que este mantém de uma visão integradora do conteúdo; por isso, de regra atua com maiores graus de liberdade frente ao professor e é mais ágil no atendimento aos alunos. Paradoxalmente, o primeiro tipo (de tutor) pode trazer problemas à administração do curso: com o tempo, ele se torna o "amigão" da turma, sempre disponível e se ajustando às idiossincrasias de cada um ("disponível 24 horas/dia") e, por vezes, mais do que orientar, contribui diretamente para a consecução dos trabalhos, em particular, o de conclusão de curso. Hábeis na troca deste tipo de informação, logo, 
na perspectiva dos alunos, o "amigão" se torna a referência, o padrão a ser seguido. Ocorre que nem todos os tutores dispõem de tempo para tal, o que dá origem às frustrações, pois não é possível atender a essa demanda (customizada) dos alunos, senão pelo que já foi dito, por não ser o propósito da formação e do processo.

Mas aqui, tal como em situações análogas, a dificuldade de encontrar o tutor ideal é grande - aquele que, além das competências técnicas reúne habilidades e atitudes como, por exemplo, mesmo à distância, consegue estabelecer elevado nível de empatia com os alunos, sem ser complacente ou piegas, indo além do que o relacionamento pessoal-profissional recomenda, consegue motivá-los nos momentos de desânimo e dificuldade, é hábil em administrar os conflitos de interesse que por vezes distanciam a coordenação, docentes e discentes (quanto à carga de leitura, trabalhos, prazos, controles, etc.) sem, contudo, perder a necessária neutralidade, sendo a efetiva "voz da razão", entre outros atributos que distinguem um bom tutor. É fora de dúvida que o tutor é um dos elementos centrais para o êxito - aprendizado de qualidade, aproveitamento e permanência, satisfação dos alunos, entre outros indicadores - da EAD de qualidade -, daí o redobrado cuidado e atenção que devem ser conferidos à sua seleção e capacitação.

Ainda que não intencionalmente, o Curso de NEGCOL combinou os dois modelos. Explica-se: em razão da experiência, alguns tutores, em geral mestrandos em final de curso ou doutorandos (muito bem avaliados) orientados pelos professores do curso, acabaram por atuar em várias disciplinas; no entanto evitou-se a sua permanência na mesma turma no decorrer do curso, sendo assim estimulada a rotatividade dos tutores (sobretudo dos considerados "os melhores tutores") entre as turmas. Ademais, contribuiu para essa circunstância, o processo seletivo utilizado: de regra iniciado pelos professores "da hora" junto aos seus orientandos (ou ex-alunos) e/ou apoiado e confrontado com as indicações da coordenação do curso com base nas avaliações realizadas pelos alunos ao término de cada disciplina; em havendo convergência, o tutor era contratado mediante pagamento de bolsa ou, excepcionalmente (em razão de aspectos normativos), como prestador de serviços.

A partir de material próprio preparado ou reunido pelos professores, tudo previamente disponibilizado na plataforma (NAVi) para os alunos, as aulas (chats) eram conduzidas pelos tutores que, reunidos no mesmo espaço físico (laboratório de informática da Escola de Administração), em caso de necessidade, podiam contar com o suporte do professor-responsável, do helpdesk, bem como das trocas de informações entre os seus pares, pois é comum que as mesmas dúvidas surjam em mais de uma turma. Em se tratando de um curso na modalidade EAD, pode parecer estranha a reunião física para a tutoria síncrona, que de fato não logrou o apoio entusiástico de alguns (poucos) tutores e professores; todavia, se revelou uma estratégia bem sucedida, seja do ponto de vista da segurança técnica (suporte de hardware e software), seja pelo fato de ser um dos poucos momentos de convívio, troca de experiências de ensinoaprendizagem e até congraçamento da equipe. Assim, se para os alunos o curso é, de fato, à distância, o mesmo não pode ser dito, na sua totalidade, no que tange às atividades da equipe executora. Ademais, um fato extremamente positivo foi "a presença" do professor em visita às turmas, prática que confere, tanto aos alunos quanto aos tutores, maior interação, motivação, comprometimento e segurança.

No que concerne à elaboração do material utilizado: 1) enquanto alguns professores preferiram prepará-lo de forma individual e posteriormente esclareceram e orientaram os tutores quanto à melhor forma de utilizá-lo e explorá-lo; 2) outros optaram por, já no momento da preparação do material, envolver os tutores. Ainda não há estudos que permitam concluir se a primeira ou a segunda estratégia foi a melhor 
sucedida. À primeira vista o segundo modelo é o mais efetivo, pois proporciona maior envolvimento da equipe, permite ao professor identificar suas próprias falhas (os tutores contribuem na revisão do material), perceber as dificuldades dos tutores, antecipar problemas e confere maior senso de participação, aumentando, assim, o comprometimento do grupo; todavia, demanda muito tempo em reuniões e discussões que, devido ao tamanho do grupo (20 tutores/disciplina), tendem a ser extensas e por isso cansativas e improdutivas, o que gerou, por vezes, descontentamento. Características opostas identificam a primeira estratégia, que prima pela objetividade e centraliza no professor as decisões críticas. A experiência do responsável pelo grupo, a natureza da disciplina, assim como o perfil da equipe (formação, personalidade, experiência, etc.) parecem ser as variáveis que devem ser analisadas em conjunto para a escolha da estratégia julgada mais apropriada. Alternativamente, há o que pode ser designado, na ausência de outra expressão, como o "modelo da Universidade Aberta do Brasil”, em que o material (apostila, sugestão de exercícios, bibliografia, vídeo-aulas) é preparado por uma equipe à parte.

\section{CONCLUSÕES}

De acordo com os resultados das pesquisas efetuadas com os alunos do curso NEGCOL conclui-se que a avaliação da capacidade e desempenho dos tutores é bastante positiva, tanto nas avaliações reativas ao final das disciplinas quanto na avaliação do apoio à orientação. A avaliação analítica realizada pela coordenação do curso deixa em aberto a questão quanto ao modelo de estruturação da tutoria, se por disciplina ou permanente, tendo em vista que, no caso do curso, foi uma mescla de ambos os modelos, em que pese a preponderância da organização do sistema de tutoria via tutor-especialista, selecionados e capacitados pelos professores das disciplinas. Há fortes indícios de que a estrutura de tutoria adotada pela coordenação do curso tenha contribuído para o bom desempenho dos tutores, haja vista a avaliação positiva manifesta na opinião da maioria dos alunos.

Dada a relevância do papel do tutor na EAD, destaca-se a centralidade do desenvolvimento de mecanismos de acompanhamento e avaliação do seu desempenho, razão essa que aponta a necessidade da continuidade de estudos, visando aprimorar os mecanismos do processo avaliativo da tutoria e, consequentemente, aprimorar a performance destes nos processos de ensino-aprendizagem mediados por TICs.

\section{REFERÊNCIAS BIBLIOGRÁFICAS}

BENTES, Roberto. A avaliação do tutor. In: LITTO, F. FORMIGA, M. Educação a distância: o estado da arte. São Paulo: Pearson Education do Brasil, 2009.

CENSO EAD.BR: relatório analítico da aprendizagem a distância no Brasil 2010. São Paulo: Pearson Education do Brasil, 2012.

CHOTGUIS, José. Avaliando a aprendizagem em EAD. Curitiba: Ed. UFPR, 2005.

IAHN, L. F. Concepções e políticas em educação a distância. In: POLAK, Y. N.S. A construção do percurso e educação a distância: formação de tutores. Curitiba: editora própria, 2002.

LONGO, Carlos Roberto Juliano. A EAD na pós-graduação. In: In: LITTO, F. FORMIGA, M. Educação a distância: o estado da arte. São Paulo: Pearson Education do Brasil, 2009.

MAIA, Carmem; MATTAR, João. ABC da EaD. São Paulo: Pearson Prentice, 2007.

NEVADO, Rosane Aragon de. Ambientes virtuais de aprendizagem. Disponível em http://www.tvebrasil.com.br/salto/boletins2005/nfa/tetxt2.htm. Acesso em: 25/10/2012.

ROSINI, A. M. As novas tecnologias da informação e a educação a distância. São Paulo: Thomson Learning, 2007. 